\title{
El estigma penitenciario y la escuela en la cárcel como estructura de mediación
}

\author{
Carmen Osuna*
}

Este artículo se basa en un trabajo etnográfico de campo desarrollado en

Palabras clave

la escuela de una cárcel de mujeres en España. Con base en el análisis de Goffman (2006 [1963]) sobre el estigma, el texto analiza cómo la escuela en la prisión actúa como una estructura de mediación en las relaciones sociales entre las mujeres y otras personas, y mitiga o magnifica el estigma penitenciario, incluyendo el modo en que ellas mismas se perciben. Es decir, mientras dentro de la cárcel "ser estudiantes" les permite traspasar el atributo de "delincuente", en actividades desarrolladas fuera de la cárcel, lo subraya. En la argumentación subyacen dos ideas fundamentales: primero, que la institución escolar se erige como un lugar "civilizatorio" en el que aprender "valores" y normas de pertenencia social; segundo, la especial significación que esta institución adquiere cuando se ubica en contextos considerados como marginales, lo que la convierte en un espacio de "segundas oportunidades".

This article is based on an ethnographic fieldwork carried out in a Women's Prison School in Spain. Based on Goffman's (2006 [1963]) analysis of stigma, we studied how prison education acts as a mediating structure in the social relations between women and other people, and mitigates or magnifies prison stigma, including the way in which inmates perceive themselves. That is to say, "being students" while still in jail allows them to transcend the depiction of "delinquent", however, performing certain activities outside of jail underlines their condition as such. Two fundamental ideas underlie the following essay: first, that the school institution stands as a "civilizing" place in which to learn "values" and social belonging norms; second, the special significance that this institution acquires when located in so-called marginal contexts, which turn the institution into a place where "second chances are built".

Keywords

School ethnography

Women'sprison

Prison stigma

Adult education

Reinsertion

Recepción: 28 de septiembre de 2020 | Aceptación: 26 de marzo de 2021

DOI: https://doi.org/10.22201/iisue.24486167e.2022.175.60166

* Profesora Contratada Doctora en el Departamento de Antropología Social y Cultural de la Universidad Nacional de Educación a Distancia (UNED) (España). Doctora en Antropología Social y Cultural. Líneas de investigación: antropología de la educación y de la escuela; antropología del confinamiento; racismo. Publicaciones recientes: (2020), “Confinamiento, agencia y reinserción. Análisis etnográfico de una vida dentro y fuera de prisión”, Revista de Antropología Social, vol. 29, núm. 1, pp. 33-45. DOI: https:// doi.org/10.5209/raso.68460; (2019), "Yo allí soy feliz, voy de lunes a viernes sin faltar': reflexiones desde una etnografía escolar en una cárcel de mujeres", Revista de Antropología Iberoamericana, vol. 14, núm. 2, pp. 277-298. DOI: https:/doi.org/10.11156/aibr.140206.CE: cosuna@fsof.uned.es 


\section{INTRODUCCIÓN}

En su conocidísima obra Estigma. La identidad deteriorada, Goffman (2006) explica que los griegos crearon el término estigma para denominar signos corporales con los que marcar a personas cuyo estatus moral era dudoso o defectuoso. Actualmente dicha marca no tiene por qué ser visible, pero el término sigue empleándose y puede reducir la identidad de una persona a un atributo profundamente desacreditador.

Según este autor, lo más interesante a la hora de abordar el estudio del estigma es prestar atención a los procesos de interacción social entre personas estigmatizadas y el resto, a las que denomina "normales". Dichos procesos darán lugar a múltiples capas de complejidad dependiendo de la visibilidad y la información social que cada estigma desprenda: encubrimiento, exhibición, inseguridad, condescendencia, etc. Así, las personas estigmatizadas oscilan constantemente entre su posición de estar desacreditadas y la posibilidad de estarlo, en función del grado de visibilidad de su marca (Goffman, 2006). En otras palabras, el atributo profundamente desacreditador siempre está presente, de un modo u otro.

Durante mi trabajo de campo en el Centro de Educación para Personas Adultas (CEPA) de una cárcel de mujeres, así como más allá de los muros de la prisión, ${ }^{1}$ la cuestión del estigma que supone estar o haber estado encarcelada siempre acompañó mis reflexiones, y es mi intención desarrollar parte de ellas en este artículo. Para ello, me basaré en Goffman (2006) y su profundo análisis, pero con la finalidad de dar un paso más allá, presentaré la escuela ${ }^{2}$ de la cárcel como una estructura de mediación, no sólo en las relaciones sociales entre las mujeres y las personas con las que interactúan en diferentes situaciones y circunstancias, sino en el modo en que permite que las mujeres traspasen lo que el autor denominó "conciencia del yo", es decir, la plena conciencia de ese atributo desacreditador (ser, o poder ser considerada como una "delincuente") que, de un modo u otro, permea todas sus relaciones sociales.

Mi objetivo es mostrar cómo la escuela, dependiendo del contexto en el que despliega sus prácticas, dentro de la cárcel o en actividades desarrolladas fuera de los muros, sirve como estructura de mediación a través de la cual el estigma se mitiga o magnifica en los procesos de interacción social. Es decir, mientras que en la cárcel asistir a la escuela permite a las mujeres traspasar el atributo de "internas", ${ }^{3}$ en algunas de las actividades desarrolladas en el exterior lo subraya y así pone en evidencia dicho atributo.

Parte fundamental de mi argumentación tiene que ver con dos ideas entrelazadas. En

\footnotetext{
I En 2015 y 2016 desarrollé un trabajo de campo etnográfico en la escuela de una cárcel de mujeres. Desde 2017 en adelante investigo los llamados "procesos de reinserción" desde una perspectiva etnográfica. Este artículo se desarrolla en el marco del proyecto de investigación "Antropología del confinamiento: construcción de redes en torno a etnografías en instituciones penitenciarias” (CAS19/00118). Comencé a pensar sobre este texto en una estancia de investigación en el CRIA-ISCTE, Lisboa, junto a Catarina Frois. Gracias, Catarina, por recibirme en tus clases y por nuestras interesantes conversaciones, pero, ante todo, por darme una familia lisboeta en plena pandemia. Gracias también a Bebes, por animarme a seguir escribiendo y por sus reflexiones en cada uno de los borradores. A Patricia Mata-Benito y Margarita del Olmo por su acompañamiento y sugerencias. A las personas que han revisado este artículo, por sus respetuosos y enriquecedores comentarios. A las colegas y participantes en el simposio del Congreso Internacional AIBR 2020, en el que presenté una comunicación basada en este artículo, por el intercambio de ideas. Gracias, siempre, a las maestras y maestros de la escuela en la cárcel; especialmente a Leticia, esperando que este artículo responda a su demanda. Y mi agradecimiento más profundo a todas las mujeres que protagonizan estas reflexiones.

2 El nombre oficial es CEPA, pero los maestros hablaban de "escuela" por ser un término más reconocible para las mujeres. En el texto utilizaré las dos denominaciones indistintamente.

${ }^{3}$ La legislación española utiliza la palabra "internas/os" para referirse a aquellas personas que están cumpliendo condena o son puestas a disposición judicial en el interior de un establecimiento penitenciario. Intento evitar esta palabra, puesto que considero que las despersonaliza. No obstante, y para el tema que me ocupa, la empleo para hacer alusión a la imagen negativa a la que se reduce la identidad de las mujeres cuando está cruzada por el estigma penitenciario.
} 
primer lugar, el modo en que la institución escolar se erige como un lugar civilizatorio donde se aprenden "valores" y normas de pertenencia social (Bourdieu y Passeron, 2001; Osuna, 2016). En segundo lugar, la especial significación que esta institución adquiere cuando se ubica en contextos considerados socialmente como marginales, donde se convierte en un espacio de "segundas oportunidades" para "llegar a ser alguien en la vida" y cumple la función social de "luchar contra la exclusión” (Castro Prieto, 2016; Planella y Jiménez-Jiménez, 2018). No en vano, en las políticas penitenciarias la educación escolar se contempla como parte del llamado "tratamiento penitenciario", es decir, el conjunto de medidas destinadas a "compensar sus carencias" y a "abordar aquellas problemáticas específicas que puedan haber influido en su comportamiento delictivo" con la finalidad de cumplir con el objetivo de la estancia en prisión: la reinserción social (Reglamento Penitenciario, RP/1996, Título V, art. 110). ${ }^{4}$

Soy consciente de que este análisis limita la posibilidad de profundizar en el modo concreto en que cada una de las mujeres convive y sobrelleva el estigma. Por supuesto, la condición de "interna" se entrecruza con múltiples factores y características sociales -incluso otros estigmas - que pueden ser tenidos en cuenta a partir de un enfoque interseccional. Sin embargo, siguiendo a Goffman (2006), y con base en el material etnográfico recogido, puedo afirmar que las mujeres protagonistas de este texto comparten suficientes situaciones y/o preocupaciones vitales como para justificar reflexiones comunes. Aun así, y aunque el análisis se centrará fundamentalmente en las interacciones sociales entre "estigmatizadas" y "normales" a través de la escuela como institución mediadora, a lo largo del texto también señalaré el modo en que el estigma (des)une a las mujeres con las que trabajé al romper la ilusión de la homogeneidad entre "internas" y mostrar el modo en que se despliega en un complejo proceso social en el que cada una participa de ambos roles, además de sufrirlos y atribuirlos (Goffman, 2006).

Por último, y antes de comenzar con la argumentación me gustaría explicitar por qué escribo este texto. En 2016 asistí, junto con el equipo de maestros y cinco mujeres, a un acto público sobre educación para adultos. En estas jornadas, tanto el director como las estudiantes hablaron sobre la escuela en la prisión: el primero, sobre legislación y organización; las segundas, sobre lo que había supuesto para ellas poder retomar sus estudios en una institución como la penitenciaria. Finalmente me dieron la palabra para que expusiera mi punto de vista como antropóloga. Al terminar fuimos a comer y una de las maestras, Leticia, ${ }^{5}$ contó un tanto indignada que varias personas le habían dado la enhorabuena por la labor que desarrollaban. “¿Enhorabuena?, ¿de qué?” fue su modo de responder al aire, y airada. Y es que, como argumentaré más adelante, las escuelas de prisiones también sufren de cierto grado de estigma e invisibilidad entre sus colegas y en la administración pública. Y también se dirigió a mí diciendo que esperaba que en algún momento les criticara, porque "sin crítica

\footnotetext{
${ }^{4}$ En este sentido existe multitud de estudios sobre procesos educativos en prisión, no sólo escolares, que analizan la oferta educativa, su pertinencia y el modo en que dichos procesos coadyuvan en la llamada "reinserción". A continuación expongo algunos argumentos que considero interesantes para la reflexión. Sáez Carreras (2010) opina que el éxito de la formación en las prisiones pasa por rebajar las expectativas en espacio-tiempo y centrarse en el momento en el que transcurre la relación educativa. Es decir, huir de promesas de futuro elaboradas a partir de retórica y centrarse en el "ahora" respecto de lo que las mujeres esperan de su paso por las aulas en el momento en que ocurre. Caride y Gradaílle (2013: 44), por su parte, inciden en este argumento y señalan además que, aunque los sistema educativo y penitenciario tienden a ignorarse, nada justifica que la educación eluda sus responsabilidades, por lo que debe "activar los compromisos políticos, institucionales y pedagógicos que se requieran". Por último, en referencia a la educación social, Del Pozo Serrano y Añaños-Brediñana (2013: 56) plantean lo que han denominado un "modelo socioeducativo emergente", que apunta a permitir la generación de programas más eficaces para superar la prisionalización y potenciar, entre otros, la autonomía y la libertad.

5 Todos los nombres son pseudónimos.
} 
no aprendemos". Escribo este artículo con su demanda en mente, esperando que les resulte de utilidad, y en un intento de explicitar cómo su lucha por visibilizar y "normalizar" su trabajo puede producir involuntariamente la (re)producción del estigma penitenciario.

\section{ESTIGMA, CONTEXTO DE INVESTIGACIÓN Y NOTAS METODOLÓGICAS}

Estoy de acuerdo con Frois (2020) cuando señala que no se puede hablar de "prisión", sino de "prisiones", porque, en un campo de análisis tan complejo, las abstracciones no funcionan. Por eso creo necesario presentar mi espacio de investigación y una serie de reflexiones metodológicas en relación con el concepto fundamental que me ocupa, el "estigma".

Comencé mi trabajo de campo etnográfico en 2015, tras obtener el permiso de la Secretaría General de Instituciones Penitenciarias y de los directores de ambas instituciones: la prisión y el CEPA. Mi investigación estaba centrada en analizar la escuela de la prisión; más concretamente, qué sentido podía tener para las mujeres retomar los estudios en un contexto como el penitenciario. Por eso, y aunque con el tiempo amplié mis espacios de observación asistiendo a múltiples eventos y actividades que no siempre tenían que ver con la escuela, fue en las aulas donde conocí a la mayoría de las mujeres con las que más tiempo compartí. Así, durante un año y medio, salvo escasas excepciones, acudí semanalmente a la prisión, asistí a clases, acompañé a estudiantes $\mathrm{y}$ al equipo de maestros en excursiones fuera de la cárcel, participé en actividades variadas y entrevisté formalmente a un total de $17 \mathrm{mu}$ jeres, además de maestros y trabajadores de la prisión. Mi trabajo de campo siempre estuvo fuertemente respaldado por la buena reputación de los maestros, y siempre percibí que decir que estaba investigando en el CEPA me dotaba, a ojos del resto de trabajadores, de un halo de confiabilidad.

No puedo negar que comencé mi trabajo de campo con ideas preconcebidas sobre el ambiente que me podía esperar y con un sinfín de inseguridades sobre cómo iba a desenvolverme en la cárcel. Por supuesto había leído literatura sobre el tema, pero, tal y como señala Hammersley (2015) en relación con las investigaciones en prisiones, la lectura jamás será comparable a las experiencias vivenciales. En un ejercicio de honestidad, lo primero que debo reconocer es que mi primer paseo por la cárcel fue muy desconcertante. Por un lado, no estaba en un lugar predominantemente cerrado y con altas torres de vigilancia, sino que abundaban los espacios abiertos, la vegetación, edificaciones bajas, caminos marcados con rosales y personas, fundamentalmente mujeres, yendo y viniendo en aparente libertad. ${ }^{6}$ Por otro lado, casi nadie portaba ningún signo visible (marca) que me permitiera saber qué rol desempeñaban, quiénes eran. ${ }^{7}$ Sólo contaba con la evidencia del género: al ser una cárcel de mujeres, ningún hombre con el que me cruzara podía ser "interno".

Mi desconcierto inicial estuvo mediado por dos cuestiones. En primer lugar, la cárcel en la que desarrollé mi investigación es un tanto sui géneris, al ser un espacio mucho más "amable y menos opresivo" que otras prisiones, en palabras textuales de una de las mujeres. Y, en segundo lugar, por la imagen exclusivamente negativa que los medios de comunicación y la producción audiovisual tienden a crear de estas instituciones y de las

\footnotetext{
${ }^{6}$ Digo explícitamente “aparente libertad” porque fue una primera impresión. La movilidad en la prisión está pautada por un régimen de seguridad que planifica y ordena las posibilidades de movimiento de cada una de las internas.

7 Las funcionarias de prisiones sí llevaban uniforme, pero otras muchas trabajadoras (psicólogas, trabajadoras sociales, etc.) no. Aunque todas las personas que no fueran "internas" debían portar una identificación, muchas veces quedaba oculta entre la ropa. Así, durante el año y medio que duró mi investigación, varias veces me confundieron con una mujer encarcelada, lo que dio lugar a situaciones que me han permitido reflexionar sobre el género como mediador de mi quehacer etnográfico (Frois et al., 2019).
} 
personas que las habitan, ya que los imaginarios que crean son de espacios lúgubres, violentos y "faltos de moral" de los que es muy difícil escapar (Walker y Worrel, 2011; Gomes, 2015). Así, aunque son espacios totalmente desconocidos para la mayoría de la sociedad, van calando en nuestro sentido común hasta naturalizarse tal y como se representan, (re)producen estereotipos y, por tanto, alimentan el estigma (Davis, 2003; Coyle, 2005). Por supuesto, esto no supone negar las complejas capas de violencia que atraviesan estas instituciones, profusamente investigadas (Orland, 1975; Foucault, 2006; Snacken, 2011; Moore y Scraton, 2014). Pero sí creo fundamental reconocerlas como espacios ambiguos en los que la "alegría, la amistad y la camaradería" también tienen cabida (Jewkes, 2015: xi; Ojeda, 2013). Para ilustrar mis argumentos, creo interesante señalar que, durante mi trabajo de campo, en 2015, se estrenó en España una serie llamada Vis a vis que se desarrolla en una cárcel de mujeres. Tal fue su éxito que ya acumula cuatro temporadas. Varios días después de la emisión del primer episodio estuve en prisión y me animé a preguntar a algunas de las mujeres con las que compartía el recreo qué opinión les merecía. Olivia estaba especialmente indignada porque el episodio había provocado que su hermana la llamara para ver si estaba bien (“¿seguro que la gente no es mala?"), y le contó que su madre se había pasado la noche llorando. Ya en un tono más jocoso, tanto ella como otras mujeres coincidieron en que "lo único que se parece es la bandeja de comida”.

El estigma penitenciario permeó mis interacciones con las mujeres tanto dentro como fuera de prisión. En su estudio, Goffman (2006) habla de cómo las relaciones sociales dependen de que el estigma sea conocido o no. En este caso, su condición de "internas" en una prisión era evidente, por lo que el "estigma penitenciario" siempre estuvo sobre la mesa.

En primer lugar, las mujeres eran muy conscientes de que estar en la cárcel reducía su identidad a una única condición, la de "criminales o delincuentes", con la imagen social que esto implica. Y eran conscientes porque, tal y como he dicho anteriormente, la representación de las prisiones a través de medios audiovisuales reduce la complejidad de estos espacios y las personas que los habitan a violencia e inmoralidad. Es decir, en línea con Goffman (2006: 48), habían realizado un "concienzudo aprendizaje" de lo que significaba el estigma penitenciario antes de verse ellas mismas afectadas. En marzo de 2016 Verónica me decía:

Yo, de verdad, que si alguien me vuelve a decir o sé por algo que ha estado en la cárcel no voy a prejuzgar. Tenemos las imágenes de las películas, todos criminales, sanguinarios, gentuza y no... No es así. Claro que hay personas con las que yo no me identifico, pero en general... No somos criminales, yo no soy una criminal (entrevista dentro de prisión).

Con estas palabras, además, Verónica rompe la supuesta homogeneidad del estigma y reclama su identidad más allá del atributo de "criminal" pero, a su vez, lo reafirma en la figura de otras personas y ejemplifica el complejo proceso apuntado por Goffman (2006) en el que los roles se entrecruzan cuando de un estigma se trata.

La preocupación por cómo podía percibirlas, y si yo era una persona en la que se podía confiar, medió constantemente la construcción de mis relaciones de confianza, sobre todo con Sofía, Olivia y Laura, las mujeres con las que más tiempo compartí. Así, la primera mañana en la que comencé la investigación en aula y el profesor me dio la oportunidad de presentar los objetivos y la posibilidad de entrevistarlas, en caso de que quisieran, Laura me dijo muy claramente que "ya se lo pensaría". Cuatro meses después me pidió que la entrevistara. Hacerlo fue un punto de inflexión en nuestra relación, ya que fue la primera vez que me habló del motivo por el que estaba encarcelada. A partir de ahí nuestras interacciones fueron mucho más fluidas y nuestra relación 
se fue consolidando. Con Olivia el proceso fue más rápido, pero muy similar. Cuando tres meses después de comenzar mi investigación la entrevisté formalmente me contó, visiblemente avergonzada, que había sido detenida por delitos de robo con violencia e intimidación. El aspecto físico de Olivia no casaba en absoluto con mi estereotipo de las personas que cometen esos delitos, así que, en un arranque de naturalidad, y sin poder evitarlo, le dije sin pensar: "ipero si no tienes ni media torta!". No había terminado de decirlo y ya estaba arrepentida. Sin embargo, y tras unos instantes, Olivia se relajó y comenzó a reírse.

Mi proceso de construcción de confianza con Laura, Olivia y Sofía, con las que sigo en contacto, fue lento y cuidadoso, y nuestra relación se fue tejiendo antes y después de las entrevistas con un firme convencimiento por mi parte: evitar la instrumentalización de mi relación con ellas para no profundizar la ineludible asimetría que ya nos separaba (Osuna, 2020). Así, poco a poco nuestra relación fue "más allá del estigma", por lo que la preocupación por lo que pudiera pensar sobre ellas dejó paso a conversaciones e interacciones más libres (que no del todo libres) de justificaciones y vergüenza, sentimiento muy común en las personas estigmatizadas (Goffman (2006; Frois, 2009).

Pero el estigma no sólo mediaba mis relaciones con las mujeres dentro de la cárcel y en lo que a nosotras concernía, sino que su peso nos obligaba a tener especial cuidado en las entrevistas que realicé fuera de prisión. Especialmente paradigmática fue la que desarrollé con Katya, una joven a quien conocí durante una de las actividades escolares fuera de los muros y con quien poco a poco fui construyendo una relación de confianza que nos llevó a vernos varias veces fuera de la cárcel, cuando ya estaba en libertad. ${ }^{9}$ En octubre de 2015 quedamos para dar un paseo y comer. Cometimos el error de sentarnos en un restaurante con las mesas muy juntas. Fue durante esa comida cuando me di cuenta del peso del estigma y de hasta qué punto limita la conversación cuando el objetivo es encubrirlo. No había ningún tipo de símbolo externo (si es que lo hay) que permitiera saber a los "normales” que nos rodeaban que Katya había estado encarcelada. Me di cuenta de que ella no quería hablar abiertamente de la cárcel cuando al sentarnos me dijo: "qué buena pinta todo, Carmen, no como en el comedor de...", y no terminó la frase, sino que agrandó los ojos y, después de unos momentos de duda, sentenció: "bueno, de ahí".

A partir de ese momento nuestra conversación se convirtió en un campo minado con el único objetivo de no pronunciar la palabra "cárcel". En un momento dado, y ante la evidencia de que la palabra aparecía más veces de las que hubiéramos pensado, me dijo por lo bajini y entre risas: "joder, qué complicao", señalando sutilmente a los de la mesa de al lado. $\mathrm{Y}$ es que, durante la conversación, igual que antes habían hecho Olivia, Laura y otras mujeres, me habló de sus estrategias para evitar que las personas de alrededor se enterasen de que había estado encarcelada, especialmente si eran conocidas, puesto que sabía que sería un estigma que no sólo les afectaría a ellas, sino también a sus familias: "si veo a gente conocida por el barrio me hago la loca, se supone que he estado currando fuera, paso dar explicaciones... no quiero que mi familia sufra".

$Y$ es que no creo que pueda negarse que la prisión es un espacio estigmatizado y que estigmatiza, al producir la reducción de la identidad social de la que hablaba Goffman:

Un individuo que podía haber sido fácilmente aceptado en un intercambio social corriente

\footnotetext{
8 Manera coloquial de decir "bofetada".

${ }_{9}$ Mantuvimos contacto hasta el 31 de diciembre de 2015, cuando me escribió por WhatsApp para desearme feliz año nuevo y mantuvimos una breve conversación. Al escribirle dos semanas después para ver qué tal había iniciado el año, y tras no recibir respuesta, llamé para descubrir que el número ya correspondía a otra persona. Lamentablemente no he vuelto a saber de ella.
} 
posee un rasgo que puede imponerse por la fuerza a nuestra atención y que nos lleva a alejarnos de él cuando lo encontramos, anulando el llamado que nos hacen sus restantes atributos (Goffman, 2006: 15).

En marzo de 2016 un grupo de mujeres, Laura entre ellas, participaba en un evento en un centro cívico. No estaba segura de la hora y no conseguía contactar con los maestros, así que decidí llamar a la recepción de dicho centro para preguntar. "Pues no sé qué decirte, ya sabes de dónde vienen. Mientras no den problemas...", fue la respuesta de la recepcionista. Este comentario me ofendió profundamente, no sólo porque hablaba de personas que me importaban, sino porque con su formulación inclusiva ("ya sabes de dónde vienen") daba por hecho que yo coincidía con su opinión y que legitimaba el estigma en una suerte de consenso social fáctico. ¿Cómo no entender el modo en que las mujeres intentan esconder su condición de "exreclusas"?

Como he indicado anteriormente, a todas ellas las conocí gracias al CEPA, ya fuera en sus aulas o en actividades desarrolladas en el exterior. Dado lo anterior, y antes de profundizar en la escuela como estructura de mediación frente al estigma, paso a explicar brevemente cómo se contempla la educación escolar en prisión, tanto desde el punto de vista legislativo como organizativo, a partir, fundamentalmente, de la perspectiva de los maestros.

\section{“'A MÍ ME IMPORTA!”. LA ESCUELA EN LA CÁRCEL DE MUJERES}

En España, la Ley Orgánica General Penitenciaria de 1979 (LPGP/1979) dispone que en cada prisión exista una escuela (Art. 55). De esta ley emana el Reglamento Penitenciario de 1996 (RP/1996), en cuyo título V se presenta el llamado "tratamiento penitenciario", o aquel conjunto de medidas destinadas a que las personas encarceladas se "reinserten" en la sociedad (Art. 110). Una de estas medidas es la educación escolar (capítulo III, título V, RP/1996), lo que habla por sí mismo de cómo la escuela se concibe como un medio para la "resocialización” (García et al., 2007; Scarfó et al., 2016). Este reglamento recoge diferentes disposiciones en las que se estimula el estudio, entre las que destacan: que las personas que no tengan títulos de enseñanza obligatoria sean examinadas para determinar el nivel de escolarización (Art. 122.1); que el seguimiento de actividades educativas será recompensado (Art. 119.1); y que podrá ser contemplado el traslado de centro penitenciario por motivos educativos (Art. 121.1).

Hasta el año 1999 los maestros de prisiones eran funcionarios que dependían de instituciones penitenciarias; es decir, aquellas personas que quisieran ejercer como docentes en las cárceles tenían que hacer una oposición ${ }^{10}$ específica para tal fin. En ese año, y en virtud del llamado "Decreto de integración" (RD1203/1999), las competencias en educación para personas adultas pasaron a cada una de las Consejerías de Educación de las diferentes comunidades autónomas, ${ }^{11}$ lo que supuso que cárcel y escuela se convirtieran en instituciones independientes y los maestros dejaran de ser "funcionarios de prisiones". La escuela de la prisión sería, entonces, un Centro de Educación para Personas Adultas, dependiente de la consejería de turno y regida por las mismas normas y finalidades.

En la práctica, el "Decreto integración" obligó a regular la coordinación entre el CEPA y la cárcel, lo que en ocasiones supone una intromisión de las políticas penitenciarias en las escolares (Osuna, 2019). ${ }^{12}$ Sin embargo, lo que también permitió fue que el claustro de

${ }^{10}$ Conjunto de pruebas específicas juzgadas por un tribunal que deben hacer las personas que quieren ocupar puestos en la administración pública en España.

${ }^{11}$ En España, las comunidades autónomas son entidades territoriales dotadas de autonomía, con representantes propios y ciertas competencias legislativas, ejecutivas y administrativas.

12 El hecho de que la institución escolar esté inserta en una institución como la penitenciaria presenta dificultades y retos de envergadura. Puesto que esta problemática subyace en el desarrollo del presente artículo, y para quién 
profesores marcara una frontera imaginaria entre ambas. Es decir, a pesar de la necesaria colaboración con las autoridades penitenciarias, y de que las aulas estaban dentro de la prisión, el equipo de maestros tenía una serie de consignas para diferenciar explícitamente los espacios, en un férreo intento de hacer de la escuela un entorno separado de la prisión, literal y metafóricamente.

La primera consigna, conscientes de que les podía condicionar, era no conocer la razón por la que sus estudiantes estaban privadas de libertad. Esto no siempre era posible, bien porque alguien se los contaba, incluyendo ellas mismas, bien porque debido a los medios de comunicación el delito era público. En una de nuestras múltiples conversaciones informales, una de las maestras me habló de cómo su relación con una de sus estudiantes se había visto afectada al conocer el motivo por el que estaba encarcelada. Este tipo de reacciones sólo ocurría con ciertos crímenes; incluso había mujeres que sufrían asilamiento entre el resto de las internas, lo que muestra la existencia de una jerarquía moral a la hora de aceptar delitos y el modo en que algunas de ellas están doblemente marcadas: por estar en la cárcel y por el motivo para estarlo (Juliano, 2010; Frois et al., 2019). ${ }^{13}$ En cualquier caso, el director del CEPA, quien cuenta con muchos años de experiencia y es consciente de la dificultad de lidiar con ciertas informaciones, siempre repetía que su trabajo "no es juzgar, sino educar". La segunda consigna consistía en repetir a sus estudiantes, una y otra vez, que "escuela y prisión no son lo mismo". Todos los docentes me hablaron de su esfuerzo para que las mujeres supieran que en el aula eran estudiantes, no "internas".
"Yo siempre insisto, de la puerta para dentro esto es la Consejería de Educación”, me decía Gonzalo, uno de ellos. Y, por último, la tercera consigna era mantener los estándares de dedicación, trabajo y exigencia que consideraban necesarios en cada uno de los niveles, aun en un contexto en el que la flexibilidad era absolutamente necesaria y parte consustancial de su trabajo, dada la necesidad de adaptar contenidos curriculares, permitir ausencias, acoger a estudiantes como oyentes, etc. (Osuna, 2019).

Por supuesto, cumplir las consignas no siempre era fácil. Antes de comenzar a desarrollar su trabajo en la escuela de una prisión, tenían que vencer sus propios prejuicios. Marcos, profesor con el que más tiempo pasé, comenzó a trabajar en la escuela de prisión tras el Decreto integración 1999, por lo que podía haber elegido cualquier otro destino. Había optado por el CEPA de una cárcel porque según otros colegas "estaba muy bien, en absoluto era horroroso", y quiso probar la experiencia a pesar del estigma:

Es verdad que muchas veces las imágenes que tenemos de prisiones son horribles, las de las películas [risas] cárceles abominables, con un guardia que es malvado y te hace la vida imposible... En fin, más o menos la imagen que tiene uno de la cárcel (entrevista, marzo de 2015).

En cuanto a mantener la escuela separada de la prisión, tanto metafórica como literalmente, no era tarea sencilla. Por un lado, las lógicas del régimen penitenciario se filtran constantemente en la vida del aula con interrupciones constantes y cotidianas: visitas de abogados, citas con otras profesionales, otras

pueda interesarle, introduzco brevemente un texto anterior en el que reflexiono sobre esta cuestión en el mismo contexto etnográfico. En el artículo "Yo allí soy feliz, voy de lunes a viernes sin faltar. Reflexiones desde una etnografía escolar en una cárcel de mujeres” (Osuna, 2019) presento un análisis teórico y empírico del modo en que ambas instituciones se imbrican y colisionan, y subrayo las contradicciones entre una legislación que fomenta la educación escolar y unas lógicas de funcionamiento que la dificultan. Asimismo, analizo el modo en que la escuela en la prisión se convierte, para las estudiantes, en un espacio de paradójica libertad en el que reconectar con ellas mismas y que les permite, además, resignificar su estancia en prisión. También recomiendo a Ghiberto y Sozzo (2014) y Schneider (2018), quienes analizan dimensiones del funcionamiento de ambas instituciones en el contexto argentino.

13 Los delitos de sangre hacia los hijos es uno de los motivos por los que las mujeres pueden sufrir mayor aislamiento. Mann (2016) analiza el tipo de discriminaciones internas que sufren los violadores en prisiones masculinas. 
actividades o trabajos remunerados, etc. ${ }^{14}$ Por otro, la obligada y necesaria coordinación entre ambas instituciones, en especial lo que se refiere al régimen de seguridad, conllevaba la imposición de los criterios penitenciarios frente a los escolares (Osuna, 2019).

Por último, y con relación a mantener estándares de dedicación y exigencia, los maestros no sólo enfrentan las circunstancias de sus estudiantes (penales, personales, curriculares, etc.) a base de flexibilidad, sino con la ocasional falta de comprensión hacia su trabajo y empeño profesional. Según el director del CEPA, cuando en un encuentro con profesionales del ámbito universitario habló sobre su trabajo en la escuela de una cárcel, la reacción de los asistentes osciló entre las bromas (“¿dais clase con pistola?"), al desconcierto y desaprobación ("las cárceles están para otras cosas"). ${ }^{15}$ Asimismo, Gonzalo, uno de los maestros, me relató el siguiente episodio:

Un día estaba preparando exámenes, un domingo por la tarde y unos amigos habían venido de visita: "pero ¿qué más da? Pon cualquier cosa, ¿a quién le va a importar?”. “A mí me importa! Son mis alumnas y se merecen mi respeto y mi trabajo" (conversación informal, 26 de marzo de 2015).

Es interesante señalar que, más allá de los fines instrumentales de la educación, todos los maestros a los que entrevisté, incluido el director, enfatizaron la función social de su trabajo. Es más, según Gonzalo, el título de enseñanza obligatoria no tiene por qué ayudarlas a encontrar un trabajo, lo que contraviene una de las finalidades básicas de la educación para adultos y la inserción laboral. ${ }^{16}$ Su máxima preocupación era dotarlas de herramientas para enfrentarse a la vida. La autoestima es una de ellas, y la trabajaba a partir de motivación y confianza en sus posibilidades.

Para el director de la escuela de la cárcel, la función social de su trabajo pasaba por la oportunidad que otorgaba a sus estudiantes de vincularse con sus familias, especialmente con sus hijos, en caso de que los tuvieran:

Sienten una gran satisfacción, por ejemplo, cuando van viendo contenidos que son referencia o que van en paralelo a los que van teniendo sus hijos en la escuela, y para ellas es muy importante, no habiendo tenido una actividad escolar, o habiendo abandonado la escuela, el verse ahora realizando cualquier tipo de actividad que pueden compartir con sus hijos (entrevista, mayo de 2015).

Y es que la escuela ofrece a las mujeres la posibilidad de reconectar con ellas mismas y con sus seres queridos, en una especie de "redención" por lo que consideran "sus errores" en la vida (Osuna, 2019). Así, en un espacio en el que su condición de "presas" es evidente, la escuela mitiga el estigma y les permite desdibujar el atributo de "internas", no sólo de cara a las autoridades penitenciarias, sino frente a ellas mismas y a sus familiares.

\section{"VENIR DICE MUCHO DE TI".}

LA ESCUELA COMO ESTRUCTURA DE MEDIACIÓN: MITIGANDO EL ESTIGMA

Como se señala en la introducción, uno de los focos de análisis más interesantes con relación

${ }^{14}$ La escuela era una de las actividades que las mujeres podían desarrollar dentro de la cárcel. También se ofrecían actividades deportivas, cursos de informática y otro tipo de talleres y formaciones que podían, además, vincularse a trabajos remunerados dentro de la cárcel.

15 Esta afirmación abre el debate sobre "para qué están las cárceles", su función y finalidad. El tema es muy complejo y la producción científica al respecto, inagotable. Recomiendo una serie de lecturas que, desde diferentes perspectivas, incluyendo la "abolicionista", abordan esta cuestión: Foucault, 2006; Davis, 2003; Coyle, 2005; Oparah, 2013; Scott, 2015; Moore y Scraton, 2016.

16 Orden ECD/651/2017, de 5 de julio, por la que se regula la enseñanza básica y su currículo para las personas adultas en modalidad presencial, a distancia y a distancia virtual, en el ámbito de gestión del Ministerio de Educación, Cultura y Deporte, en: https://www.boe.es/buscar/doc.php?id=BOE-A-2017-7983 (consulta: 20 de julio de 2020). 
al "estigma" es atender a las relaciones entre las personas estigmatizadas y lo que Goffman denomina "los normales". Estos procesos de relación dan lugar a múltiples y cruzadas reacciones y sensaciones: inseguridad, exposición, actitudes desafiantes, etc. Pero dentro de prisión, y con relación al estigma penitenciario (estar o haber estado en prisión), no hay dónde esconderse. Todas las personas "normales" que interactúan con ellas ya conocen su marca y, por tanto, las mujeres ya están - ya se saben- desacreditadas. Por supuesto, y como también se señaló, el estigma penitenciario se entrecruza con otros muchos. Entre otras cosas, con el del tipo de delito por el que están encarceladas. Así, aunque los maestros querían hacer de la escuela un espacio más allá de prisión, ya he apuntado cómo los motivos de encarcelamiento podían suponer una barrera más o menos presente en sus relaciones.

Pero lo que quiero destacar sobre la escuela, en relación con su capacidad de mitigar el estigma penitenciario y superar el atributo desacreditador, es el modo en que ofrece la doble posibilidad de "normalización" y "normificación” (Goffman, 2006: 44). En primer lugar, la escuela propicia la posibilidad de tratar a sus estudiantes como si fueran "normales", como si, en vez de en una prisión, las aulas se desarrollaran en cualquier CEPA fuera de los muros. En segundo lugar, permite su "normificación”, es decir, les permite a ellas desplegar esfuerzos para presentarse como estudiantes "normales", no como "internas". Estas dos posibilidades, entretejidas entre sí, se enlazan a su vez con el modo en que la institución escolar se erige como un espacio de aprendizaje social donde aprender a ser "buenas ciudadanas" y "personas de provecho" insertas en la sociedad.
En febrero de 2015, el director del establecimiento penitenciario me confirmó que asistir a la escuela era voluntario, si bien prioritario para aquellas mujeres analfabetas o carentes del título de secundaria. Según sus propias palabras:

[La formación escolar] es importante para desenvolverte en la vida y adquirir capacidad de decidir, capacidad de resolverte tus propios problemas, de enfrentarte a un conflicto, a una situación de abuso de los demás... Tener los conocimientos básicos para defenderte en la vida y para que nadie decida por ti (entrevista, febrero de 2015).

Asimismo, según el educador ${ }^{17}$ al que pude entrevistar en mayo de 2016, y en relación con la importancia que se da a la formación en el tratamiento penitenciario conducente a la reinserción, una de las primeras preguntas que deben hacerle a las mujeres versa sobre su nivel de estudios. En caso de abandono temprano recomiendan asistir a la escuela para subsanar sus "deficiencias".

Llegados a este punto, creo interesante señalar que una de las razones que se relaciona con los índices de criminalidad de las mujeres es el abandono escolar (Sáez, 2010). Desde el punto de vista del director de la cárcel y del educador, parece posible establecer una conexión en sus discursos entre la falta de formación escolar y la falta de aptitudes y competencias para gestionar circunstancias vitales $y$, en consecuencia, cometer delitos. ${ }^{18}$ La escuela se erige, así, como un espacio de "prevención, asistencia, inclusión y reinserción social” (Caride et al., 2015: 8).

Las mujeres que conocí en la escuela eran muy conscientes del rol de la escuela como

17 En España, la figura del educador en prisión no es la misma que la de maestro de CEPA. Los educadores son funcionarios cuya primera función, establecida por RD 1201/1981, es "atender al grupo o subgrupo de internos que se les asigne, a quienes deberán conocer lo mejor posible, intentando mantener con ellos una buena relación personal, y a los que ayudarán en sus problemas y dificultades durante su vida de reclusión, intercediendo, presentando e informando ante la Dirección del Establecimiento sus solicitudes o pretensiones" (RD 1201/1981, art. 296).

18 Autoras como Juliano (2006) e Imaz (2007) denuncian que la criminalidad entre las mujeres suele estar asociada a comportamientos inmaduros y raras veces a acciones conscientes de contestación social. 
espacio "normificador", hasta el punto de utilizarlo en su propio interés. Es decir, muchas de ellas me dijeron que se habían apuntado no sólo por los beneficios prácticos que podían obtener, ${ }^{19}$ sino porque ir a la escuela "dice mucho de ti":

Sinceramente, yo cogí la escuela por puntos, porque además venir dice mucho de ti. Si tienes seis horas por la mañana, no es lo mismo que te vean jugando al parchís, andando por el patio, que viniendo a la escuela, no es lo mismo. Si vas a la escuela se supone que tienes interés en ser mejor (entrevista a Maica, marzo de 2015).

Que ir a la escuela fuera un rasgo positivo para las autoridades penitenciarias era vox populi entre las mujeres. Algunas de ellas me contaron que habían decidido matricularse por consejo de otras compañeras; una tarde de abril de 2016 presencié una charla grupal en el patio en el que una mujer más veterana le recomendaba a Fátima, recién llegada: "tú lo que tienes que hacer es ir a la escuela y ocupar tu tiempo para que vean que quieres cambiar".

Pero su interés en la escuela no sólo pasaba por dar una buena imagen de ellas mismas. Aunque todas reconocieron haberse apuntado por fines instrumentales, todas afirmaron haber encontrado en las aulas un espacio en el que sentirse "normales y libres" y olvidarse, aunque fuera por momentos, de que estaban en una prisión. Para algunas de ellas, además, la escuela era una oportunidad para "corregir” su imagen social y mitigar el estigma, no sólo en relación a ellas mismas, sino con sus familias. Por un lado, mujeres que no se creían capaces de estudiar se veían haciéndolo y superando las diferentes pruebas, lo que repercutía en su autoestima. Por otro, y en relación a la función social que destacaba el director de la escuela, se mostraban felices del orgullo de sus familias y de sentirse útiles al ayudar a sus hijos o nietos con las tareas:
Van pasando los meses y tras la primera evaluación dices "oye, pues valgo" y te preguntas “ipor qué lo dejaría yo?", y luego parece que te vas animando (entrevista a Maica, marzo de 2015).

A mí estar en la escuela me hace mucha ilusión porque de pequeña no tuve la oportunidad, y cuando hablo con mis nietos se lo pasan estupendo conmigo. El otro día el pequeño me preguntó “yaya, ¿ya sabes dividir?". Y se puso tan contento, dice que me va a llamar para que le ayude (conversación informal con Triana, marzo de 2016).

Por supuesto, entre las "internas" existen diferencias y jerarquías que les hacen establecer categorías que implican la existencia de "normales" vs. "estigmatizadas", y en esta clasificación las drogodependientes son especialmente vulnerables. El primer día que pasé en prisión oí hablar de la existencia de módulos "conflictivos". La primera vez que pregunté a las mujeres del aula sobre esta denominación, una de ellas contestó: "pues donde meten a las yonquis y eso, no van a meter a la gente... Bueno... A la gente 'normal'" Y, sin embargo, en la escuela estaban juntas, independientemente de sus causas o de otros criterios penales, donde se recrea el espejismo que mejor (re)crea la escuela: "que todas son iguales". Más allá de sus delitos, las mujeres asistían a clase, hacían deberes, exámenes, debatían... Y todo ello a través del esfuerzo de un grupo de maestros cuya máxima finalidad era "normalizarlas" y tratarlas como a estudiantes de un CEPA cualquiera. ¿Y fuera de prisión?

\section{"Personas en Circunstancias ESPECIALES”. LA ESCUELA COMO ESTRUCTURA DE MEDIACIÓN: MAGNIFICANDO EL ESTIGMA}

Como ya he explicado, la escuela de la prisión era un CEPA dependiente de la Consejería de

${ }^{19}$ El título X del capítulo VI del RP/1996 establece un sistema de recompensas por la participación en actividades dentro de prisión. 
Educación, con sus propias normas y dinámicas internas. Así, dos veces al año, el equipo de maestros programaba salidas extraescolares que, a modo de excursión, permitía a sus estudiantes participar de actividades de ocio de diversa índole: ${ }^{20}$ visitas a museos, asistencia a eventos en centros cívicos, excursiones al aire libre, etc. Una de las cosas que más me sorprendió cuando participé en las excursiones fue el absoluto anonimato de las mujeres, la absoluta invisibilidad del estigma penitenciario. Paseaban por las calles, comían en el restaurante, miraban escaparates... No había nada en ellas que pudiera hacer pensar que estaban internas en una prisión. Nadie tenía manera de saber que veníamos de la cárcel, y ellas solían bromear con ello. En la primera salida nos cruzamos con un grupo de policías jóvenes y unas cuantas les saludaron muy amablemente para, unos metros más adelante, comenzar a reírse y decir “isi ellos supieran!". Fuera de la cárcel, el atributo profundamente desacreditador que implica estar encarcelada queda en suspenso.

De hecho, cuando le pregunté al director de la escuela si las personas que recibían a las estudiantes sabían de donde procedían, me dijo que no porque "no le incumbe a nadie", y que únicamente lo mencionaban si era estrictamente necesario.

Sin embargo, de vez en cuando las mujeres también participan en jornadas de Centros de Educación para Personas Adultas y en otras actividades en las que su condición de estudiantes de un CEPA inserto en una prisión queda al descubierto. Ya he señalado que los profesores del CEPA suelen enfrentarse al desconocimiento sobre su trabajo debido al contexto en el que se desarrolla, y que uno de sus principales intereses es reivindicarlo, al normalizarlo y darle visibilidad. Una forma de hacerlo es, precisamente, explicar las particularidades de su trabajo y defender la importancia de la educación escolar en un contexto como la prisión. ¿Y quién mejor que las propias estudiantes para explicar lo que supone poder volver a la escuela en la cárcel? Con esa intención, en marzo de 2016 el equipo de maestros del CEPA participó en unas jornadas a las que me referí anteriormente. El director explicó la escuela desde la perspectiva legislativa y organizativa, y las estudiantes se hicieron cargo de explicar de primera mano su propia experiencia. Algo que, aun sin pretenderlo, magnificó el estigma. En las salidas en las que las estudiantes eran anónimas, el atributo profundamente desacreditador era invisible. En esta salida, fue el punto de partida.

Dice Goffman (2006) que una de las diferencias entre estar desacreditada y ser susceptible de descrédito radica en qué hacer con la información en las interacciones. Si el estigma no se conoce, es decir, si todavía no estás desacreditada, se despliega un sinfín de posibilidades sobre cómo manejar esa información dependiendo de con quién estás. El "encubrimiento" es una de las opciones, tal y como intentaba Katya en nuestra comida. En estas jornadas, encubrirlo ya no era una opción porque todo el mundo sabía que provenían de la escuela de una cárcel. Por eso me sorprendí mucho cuando Ángela, al entrar al espacio en el que se iba a desarrollar el acto, me preguntó bajando la voz: “ipero hay que decir de dónde venimos?". Cuando le dije que ya lo sabían, me miró muy fijamente y me dijo: "ay, por favor, que no me reconozcan", mostrando una clara preocupación por su imagen pública y lo que sus conocidos pudieran pensar de ella, en la misma línea que Katya. Estoy segura de que el director había sido muy explícito con las mujeres acerca de dónde iban a participar, si es que ellas querían; sin embargo, el desconcierto de Ángela no sorprendió a Leticia, una de las maestras. Cuando más tarde se lo comenté al director, con ella delante, su reacción fue afirmar: "No me extraña, nos pasamos el día diciéndoles que 'la escuela no es la cárcel' y luego mira...."

20 Para poder organizarlas, el director de la escuela circunscribía estas actividades en las llamadas "salidas programadas o terapéuticas" dispuestas en el artículo 114 del Reglamento Penitenciario. 
Más allá de lo ya señalado, lo que me gustaría destacar de este evento, en relación a la magnificación del estigma, es el modo en que las diferentes mujeres manejaron su marca y cómo reaccionó la audiencia. Así, las interacciones oscilaron entre la condescendencia, la inseguridad, el "retraimiento y la bravata" (Goffman (2006: 29). Durante la presentación de las jornadas, uno de los representantes de la Consejería llamó la atención sobre la presencia de unas estudiantes "muy meritorias" y dijo unas palabras que hicieron que me revolviera en el asiento y murmurara un pequeño improperio: "no es lo mismo enseñar a mamás estudiantes que a personas que están en... Bueno, en circunstancias especiales". Lamentablemente, Ángela me escuchó y cometí el error de repetirle lo que había dicho. Ella estaba tan nerviosa que no se había dado ni cuenta. "Pues empezamos bien", fue su respuesta.

Después de la intervención del director fue el turno de las mujeres. Resulta interesante que todas aludieron en su breve discurso a que estaban en prisión por haber cometido un “error”. Una de ellas, Nadia, admitió estar profundamente avergonzada. El resto dijo estar cumpliendo su condena dignamente, y que la vergüenza ya no tenía cabida, si es que la había tenido. Así, partiendo de la base de que el estigma penitenciario era sobradamente conocido, todas ellas reaccionaron poniéndolo sobre la mesa desde el primer momento, y se posicionaron frente a él de distintas maneras. Especialmente paradigmáticas, por opuestas, fueron las posiciones de Nadia y Nora. Mientras la primera partió de una actitud retraída, Nora se mostró desafiante:

Al estar dentro de prisión nos sentimos avergonzadas, apenadas por muchas cosas, por las circunstancias que nos tienen ahí (Nadia, notas en cuaderno de campo).

Un error lo tenemos cualquiera, y tampoco me voy a avergonzar de donde estoy porque es algo que le puede pasar a cualquiera en la vida (Nora, notas en diario de campo).

Ángela, por su parte, necesitó dos intentos para hablar. En el primero se puso a llorar y se disculpó por estar muy nerviosa; en el segundo, algo más templada, también comenzó pidiendo perdón por sus errores. Todas ellas hablaron de cómo la escuela, más allá de permitirles obtener un título que esperaban poder rentabilizar, les ayudaba a sobrellevar su condena, en la línea de la función social que siempre enfatizaba el director.

La respuesta del público fue unánime: primó la condescendencia. Los aplausos fueron muy sonoros, y en el turno de preguntas todas las personas que hablaron comenzaron alabando su esfuerzo, su capacidad y su espíritu de superación. De este modo, ir a la escuela, acción absolutamente cotidiana $-\mathrm{y}$ obligada- para el resto de las personas se convertía, a los ojos (condescendientes) de los "normales", en una proeza excepcional.

Después de las jornadas fuimos a comer. Y, tal y como expliqué en la introducción, Leticia mostró su indignación cuando nos contó que muchas personas se habían acercado a darle la enhorabuena: “ ¿enhorabuena?, ¿de qué?”. Su indignación provenía, precisamente, del modo condescendiente en que sus colegas habían interpretado su trabajo, dotándole del valor añadido de trabajar en un contexto inusual, con todo lo que entendían que suponía.

Sin haberlo pretendido, "normalidad" y estigma se habían convertido en dos caras de la misma moneda:

La situación especial del estigmatizado reside en que por una parte la sociedad le dice que es un miembro del grupo más amplio [estudiantes de un CEPA] ...y, por otra, que hasta cierto punto es "diferente" y que sería disparatado negar esa diferencia [estudiantes de un CEPA inserto en una prisión] (Goffman, 2006: 126). 
ESCUELA Y CUESTIÓN DE

\section{EXPECTATIVAS. REFLEXIONES A MODO DE CONCLUSIÓN}

A lo largo del texto me he basado en algunas ideas del profundo estudio de Goffman sobre el estigma para ejemplificar el modo en que las estudiantes de la cárcel de mujeres convivían con él, y cómo la escuela actuaba como una estructura de mediación que, dependiendo del contexto en que desplegara sus prácticas, lo mitigaba o magnificaba.

Soy consciente de que en mi análisis aludo a situaciones específicas que me han permitido construir este hilo argumental. Ahora bien, creo importante señalar que tanto dentro como fuera de la cárcel, y en la medida en que el estigma siempre estaba presente, ambos contextos son escenarios en los que se magnifica y mitiga, dependiendo de las prácticas sociales desplegadas. Dentro de prisión, el estigma penitenciario era evidente. Pero las mujeres convivían con diferentes estigmas que se magnificaban contextualmente, como el de la drogadicción. Fuera de la cárcel, en las actividades en las que eran simplemente "estudiantes de un CEPA" el atributo profundamente desacreditador quedaba mitigado, aunque el encubrimiento cruzara sus interacciones.

Dicho esto, todavía queda una idea por explicitar: cuando las interacciones sociales están mediadas por un estigma, al final, casi todo se reduce a expectativas (Goffman, 2006). Así, los atributos, cuando son profundamente desacreditadores, reducen la identidad de las personas, moldean lo que se puede esperar de ellas y causa sorpresa cuando no se cumple. La escuela también mediaba en las expectativas que los "normales" tenían de las mujeres, así como en su "conciencia del yo".

En contextos considerados como marginales y/o en relación a personas con historias de abandono temprano, la escuela es una institución que, tal y como señalan Trueba y Spindler (1989), se concibe como el lugar para "llegar a ser alguien", para "encontrar un lugar en la sociedad". Por su parte, Gilmore y Smith (1989) argumentan que se trata, incluso, de un espacio de redención. Y todas esas interpretaciones subyacen en el modo en que la escuela produce cierta "revalorización del yo" en las mujeres, y desdibuja la "conciencia del yo" (interna) que solía imponerse en sus relaciones con los otros. Como ya he señalado, más allá de los fines instrumentales, todas ellas rescatan el hecho de que retomar los estudios les permite conectar con sus familias, e incluso con ellas mismas (Osuna, 2019). Descubren que "valen" para los estudios, ayudan a sus hijos y nietos en las tareas y se proyectan en un futuro en el que el título de la enseñanza secundaria obligatoria (ESO) les abre puertas para encontrar un nuevo lugar, para empezar de cero:

Van pasando los meses y tras la primera evaluación dices "oye, pues valgo" y te preguntas “ipor qué lo dejaría yo?” y luego parece que te vas animando... Cuando salga no me gustaría dejarlo [estudiar]; quisiera sacarme psicología infantil y optar a ser trabajadora social... Que los profesores tengan buena opinión de ti también ayuda, al principio yo me pongo una barrera para que la gente no me conozca y luego pues que te digan "Maica, tú vales", eso me lo dijo Gonzalo... He dejado a mi marido, ya sabes, y algunas compañeras me dicen que ahora qué voy a hacer, pues que digo yo que una mujer separada sin hijos tira, ¿no? No seré la primera (entrevista a Maica, marzo de 2015).

En cuanto a las expectativas de "los normales", ya he señalado cómo desde el "tratamiento penitenciario" la escuela se concibe como un elemento de reinserción, algo que también se trasluce en el discurso del director y del educador. Las mujeres eran conscientes de cómo ir a la escuela "hablaba bien de ellas" y utilizaban esta circunstancia en su propio beneficio. Según me contó Juana, no querer perderse la posibilidad de culminar el curso fue el motivo que argumentó para retrasar su salida de la cárcel una vez que le habían 
concedido el tercer grado. ${ }^{21}$ El motivo real, según sus propias palabras, era no querer ir al centro de inserción social:

A mí la escuela me da igual, qué quieres que te diga, yo lo que quiero es quedarme aquí el tiempo que me queda, recuperarme bien. Aquí tengo mi chabolo, ${ }^{22}$ mis cositas, mis terapias. Estoy hasta el coño, pero estoy bien... El CIS es cutre y hay gentuza (conversación informal, mayo de 2015).

Por cierto, una vez más, estas palabras reflejan la existencia de jerarquías entre las propias "internas", ya que pone de manifiesto que no solo sufren el estigma, sino que también lo atribuyen.

Las familias, por su parte, parecen mostrarse orgullosas de que hayan retomado los estudios. No tuve contacto intenso con ningún familiar, por lo que mis interpretaciones emanan de lo que ellas mismas me decían:

Mi familia está muy contenta de que esté aquí en la escuela y yo también. Tanto tiempo sin estudiar y estoy aprobando... Mi hermano está muy orgulloso de mí, mucho (entrevista a Olivia, abril de 2015).

Con respecto a los asistentes a las jornadas, ya he argumentado cómo la condescendencia reinó en el ambiente. Que mujeres encarceladas (¿"criminales"?, ¿ delincuentes"?) fueran a la escuela se percibe como un acto excepcional, tanto como el del equipo de maestros que enfrenta la tarea. Para la audiencia, que estas mujeres centraran sus esfuerzos en el aula significaba que querían ser "mejores personas".

En lo que a mí respecta, comencé mi trabajo de investigación con muchos prejuicios y el estigma penitenciario también permeó mi relación con las mujeres. Poco a poco, y con algunas de ellas, fui construyendo una relación más allá del estigma. Y, sin embargo, sé que no es suficiente. El primer día que vi a Sofía fuera de prisión recibí un SMS de su madre:

Si hola Carmen mira no me conoces pero soy la madre de Sofía. Lara. Me llamo Lara. Me ha dicho que está contigo desayunando pero no la localizo [sic] (SMS, noviembre de 2015).

Cuando se lo dije miró su teléfono y vio varias llamadas perdidas. "Qué pesada, no se fía un pelo", fue su reacción. Sofía tenía un largo historial de drogadicción y, según me dijo, cuando no la localizaban ya la imaginaban consumiendo. Devolvimos la llamada a su madre y me puse al teléfono para tranquilizarla. Sofía sufre el doble estigma de exreclusa y drogadicta y no puede escapar de ellos. Todavía seguimos en contacto. Cuando en alguna ocasión no he conseguido localizarla, ese mismo pensamiento (temor) ha cruzado en mi cabeza. ¿Dónde me deja eso?

tenciarias", Revista Educación, núm. 360, pp. 36-47. DOI: https://doi.org/10.4438/1988592X-RE-2013-360-219

CARIde, José Antonio, Rita Gradaílle y María Belén Caballo (2015), "De la pedagogía social como educación, a la educación social como pedagogía”, Perfiles Educativos, vol. 37, núm. 148,

${ }^{21}$ Las personas clasificadas en tercer grado pueden llevar un régimen de vida en "semilibertad", lo que implica salir de la prisión y volver a dormir al centro a otro establecimiento, como un centro de inserción social (CIS) (RP/1996, art. 100 yss.).

22 Celda. 
suplemento "Pedagogía social y educación social”, pp. 4-11.

Castro Prieto, Oscar (2016), "Educación social en contextos de encierro", en Revista de Educación Social, núm. 22, en: https://eduso. net/res/revista/22/el-tema-colaboraciones/ educacion-social-en-contextos-de-encierro/ (consulta: 3 de septiembre de 2020).

Coyle, Andrew (2005), Understanding Prison: Key issues in police and practices, Londres, McGraw-Hill Education.

Davis, Angela (2003), Are Prisons Obsolete?, Nueva York, Seven Stories Press.

Del Pozo Serrano, Francisco José y Fanny T. Añaños-Brediñana (2013), "La educación social penitenciaria. ¿De dónde venimos y hacia dónde vamos?", Revista Complutense de Educación, vol. 24, núm. 1, pp. 47-68. DOI: https:// doi.org/10.5209/rev_RCED.2013.v24.n1.41191

Foucault, Michael (2006 [1976]), Vigilar y castigar, Buenos Aires, Siglo XXI Editores.

Frois, Catarina (2009), Dependência, estigma e anonimato nas associações de 12 passos, Lisboa, Imprensa de Ciências Sociais.

FroIs, Catarina (2020), Prisões, Lisboa, Fundação Francisco Manuel Dos Santos.

Frois, Catarina, Carmen Osuna y Antónia Pedroso de Lima (2019), "Ethnography in Contexts of Incarceration: Exploring potentials and limits”, Cadernos Pagu, núm. 55, en: https:// www.scielo.br/j/cpa/a/bMgjPBWDJy4srKbG PHLthSp/?lang=en\&format=pdf (consulta: 20 de diciembre de 2021).

García, María B., Silvia Vilanova, Eduardo del Castillo y Agustín Malagutti (2007), "Educación de jóvenes y adultos en contextos de encierro. Una experiencia de extensión universitaria en la escuela de un penal", Revista Iberoamericana de Educación, vol. 44, núm. extra 1, pp. 1-9.

Ghiberto, Luciana y Máximo Sozzo (2014), “Prisión y educación. Relaciones, tensiones y paradojas", Nova Criminis: Visiones Criminológicas de la Justicia Penal, núm. 8, pp. 167-209.

Gilmore, Perry y David Smith (1989), "Mario, Jesse and Joe: Contextualizing dropping out", en Henry Trueba, George Spindler y Louis Spindler (eds.), What do Anthropologist Have to Say about Dropouts?, Bristol, The Farmer Press, pp. 79-92.

Gobierno de España (1979), Ley Orgánica 1/1979, de 26 de septiembre, General Penitenciaria (BOE $n^{\circ} 239$, de 5 de octubre), Madrid, Jefatura de Estado.

Gobierno de España (1981), Real Decreto 1201/1981, de 8 de mayo, por el que se aprueba el Reglamento Penitenciario (BOE $\mathrm{n}^{\circ} 149$, de 23 de junio), Madrid, Ministerio de Justicia e Interior.
Gobierno de España (1996), Real Decreto 190/1996, de 9 de febrero, por el que se aprueba el Reglamento Penitenciario (BOE $n^{\circ} 40$, de 15 de febrero), Madrid, Ministerio de Justicia e Interior.

Gobierno de España (2017), Orden ECD/651/2017, de 5 de julio, por la que se regula la enseñanza básica y su currículo para las personas adultas en modalidad presencial, a distancia y a distancia virtual (BOE $\mathrm{n}^{\circ} 162$, del 8 de julio), Madrid, Ministerio de Educación, Cultura y Deporte.

GofFman, Erving (2006 [1963]), Estigma. La identidad deteriorada, Buenos Aires, Amorrortu.

Gomes, Silvia (2015), "Media e crime. Dos media e da construção das realidades criminais", en Manuela Ivone Cunha (org.), Do crime e do castigo. Temas e debates contemporáneos, Lisboa, Mundos Sociais, pp. 81-98.

Hammersley, Martyn (2015), "Research 'Inside' Viewed from 'Outside': Reflections on prison ethnography”, en Debora H. Drake, Rod Earle y Jennifer Sloan (eds.), The Palgrave Handbook of Prison Ethnography, Hampshire, Palgrave Macmillan, pp. 21-39.

IMAZ, Elixabete (2007), "Mujeres reclusas, mujeres invisibles", en Bárbara Biglia y Conchi San Martín (coords.), Estado de wonderbra: entretejiendo narraciones feministas sobre las violencias de género, Barcelona, Virus Editorial, pp. 189-197.

Jewkes, Yvonne (2015), "Foreward”, en Debora H. Drake, Rod Earle y Jennifer Sloan (eds.), The Palgrave Handbook of Prison Ethnography, Hampshire, Palgrave Macmillan, pp. ix-xiv.

Juliano, Dolores (2006), Excluidas y marginales, Madrid, Cátedra.

Juliano, Dolores (2010), "La criminalización de las mujeres. Estigmatización de las estrategias femeninas para no delinquir", en Fanny T. Añaños (coord.), Las mujeres en las prisiones. La educación social en contextos de riesgo y conflicto, Barcelona, Gedisa, pp. 25-44.

Mann, Ruth E. (2016), "Sex Offenders in Prison", en Yvonne Jewkes, Jamie Bennet y Ben Crewe (eds.), Handbook on Prisons, Londres/Nueva York, Routledge, pp. 246-264.

Moore, Linda y Phil Scraton (2014), The Incarceration of Women. Punishing bodies, breaking spirits, Londres, Berghahn.

OJEDA, Soledad (2013), “'Cárcel de mujeres'. Una mirada etnográfica sobre las relaciones afectivas en un establecimiento carcelario de mediana seguridad en Argentina", Revista Sociedad y Economía, núm. 25, pp. 237-254.

Oparah, Julia C. (2013), "Why no Prisons?”, en David Scott (ed)., Why Prison?, Cambridge, Cambridge University Press, pp. 278-300.

Orland, Leonard (1975), Prisons: Houses of Darkness, Nueva York, The Free Press. 
Osuna, Carmen (2016), "Entre desfiles y wiphalas: escuela y construcción de ciudadanía en Bolivia”, Revista de Dialectología y Tradiciones Populares, vol. 71, núm. 1, pp. 269-290. DOI: https://doi.org/10.3989/rdtp.2016.01.011

Osuna, Carmen (2019), "'Yo allí soy feliz, voy de lunes a viernes sin faltar': reflexiones desde una etnografía escolar en una cárcel de mujeres", Revista de Antropología Iberoamericana, vol. 14, núm. 2, pp. 277-298. DOI: https:// doi.org/10.11156/aibr.140206

Osuna, Carmen (2020), "Confinamiento, agencia y reinserción. Análisis etnográfico de una vida dentro y fuera de prisión”, Revista de Antropología Social, vol. 29, núm. 1, pp. 33-45. DOI: https://doi.org/10.5209/raso.68460

Planella, Jordi y Joxe Jiménez-Jiménez (2018), “Espacios reales y simbólicos de la pedagogía social: la praxis de la redención, entre el control y la emancipación”, Opción, núm. 86, pp. 547-576.

SÁEz Carreras, Juan (2010), “Existe una educación específica para las mujeres en las prisiones? Algunas reflexiones desde la lógica profesional", en Fanny T. Añaños (coord.), Las mujeres en las prisiones. La educación social en contextos de riesgo y conflicto, Barcelona, Gedisa, pp. 101-122.

Scarfó, Francisco José, María Eugenia Cuellar y Deborah Sabrina Mendoza (2016), "Debates: sobre el rol de la escuela y de los educadores de adultos en las cárceles", Cadernos Cedes, vol. 36, núm. 98. DOI: https://doi.org/10.1590/ CC0101-32622016162883
Schneider, Gretel (2018), "Cuando la escuela acontece en la cárcel”, Contextos de Educación, núm. 24, pp. 3-13, en: http://www2.hum. unrc.edu.ar/ojs/index.php/contextos/article/ view/727 (consulta: 25 de marzo de 2021).

Snacken, Sonja (2011), Prisons en Europe. Pour une pénologie critique et humaniste, Bruselas, Larcier.

Scotт, David (2015), "Walking amongst the Graves of the Living: Reflections about doing prison research from an abolitionist perspective", en Debora H. Drake, Rod Earle y Jennifer Sloan (eds.), The Palgrave Handbook of Prison Ethnography, Hampshire, Palgrave Macmillan, pp. 40-58.

Trueba, Henry, George Spindler y Louise Spindler (1989), "Introduction", en Henry Trueba, George Spindler y Louis Spindler (eds.), What do Anthropologist Have to Say about Dropouts?, Bristol, The Farmer Press, pp. 1-6.

Walker, Stephanie y Anne Worral (2011), "Life as a Woman: The gendered pains of indeterminate imprisonment", en Yvonne Jewkes y Helen Johnston (eds.), Prison Readings. A critical introduction to prisons and imprisonment, Nueva York, Routledge, pp. 253-267. 